\title{
Anton Rochel.
}

Von Josef Ullepitsch.

Jedem Botaniker in Furopa ist der vorstehende Name bekannt, obgleich der Mann, der ihn trug, schon bei 40 Jahre im kühlen Schosse der Erde schlummert. Ich glaube, dass eine kurze Beschreibung seines Lebenslaufes Vielen erwünscht sein dürfte, und will davon so viel erzählen, als mir noch theils aus seinen mündlichen Mittheilungen erinnerlich ist, theils ich Notizen entnommen habe, die mir sein noch lebender Sohn Alois Rochel, k. u. Bergrath a. D. freundlichst zu Gebote stellte.

Anton Rochel wurde am 18. Juni 1770 zu Neunkirchen am Steinfelde in Niederösterreich geboren. Sein Vater Mathias war Bürger und Kanfmann daselbst. Seine Mutter Maria Anna, geborene Bayerl aus Aflenz in Steiermark, verlor er schon in früher Kindheit durch den Tod. Er erhielt eine unfreundliche Stiefmutter und musste ihr schon mit 8 Jahren aus dem älterlichon Hause weichen.

Er wurde zu einem Anverwandten nach Kuttenberg in Böhmen gebracht, wo er in der damaligen Jesuitenschule den ersten Unterricht erhielt.

Am 26. September 1785, also in seinem 15. Jahre, meldete er sich beim Vorsteher des Hauptgremiums der bürgerlichen Wundärzte in Wien wegen Erlernung der Wundarzneikunst und wurde zu diesem Behufe einem Herrn Kachelmayer übergeben. Am 19. Mai 1788, also vor Ablauf der jenerzeit vorgeschriebenen drei Lehrjahre, wurde er freigesprochen und als Wundarzneigeselle bestallt.

Während dieser Lehrjahre studirte er schon Botanik und vervollkommnete sich in der lateinischen Sprache, von deren Kenntniss er später in seinem Werke "Plantae Banatus rariores" glänıenden Beweis gab.

Gleich 1788 trat er in die Armee als chirurgischer Gehilfe und machte als solcher den letzten Feldzug gegen die Türken mit. Er war bei verschiedenen Bataillen und bei der Belagerung von Ada-Kale (Orsowa) zugegen, und wäre vor lotzterem Orte mitten in ärztlicher Thätigkeit beinahe von einem Bombensplitter getroffen worden.

Trotz der Märsche und Spitalsdienst nützte er die Zeit des Krieges so fleissig aus, dass er, nach Wien zurückgekehrt, schon am 28. September 1792 von der medicinischen Facultät der Universität in Wien zum Magister Chirurgiae promovirt worden ist.

Er verblieb im Armeeverbande und machte als Wundarzt den ersten Krieg gegen Frankreich mit. Er wurde von den Franzosen gefangen genommen und nach Dijon gebracht. Mit anderen Gefangenen wurde auch er ausgelöst und diente weiter in der Armee, theils in Frankreich, theils in Holland und Belgien.

Auch diese Zeit nützte er fleissig zur Vermehrung seiner Kenntnisse aus. Er erlernte nicht nur vollkommen französisch, sondern 
war im Stande, gleich nach seiner Rückkehr nach Wien an der Universität die Prüfungen als Geburtshelfer abzulegen, und erhielt am 5. November 1798 das Diplom als Magister obstetritiae.

Nun trat er ans der Armee und liess sich vorerst im Hradischer Kreise Mährens als praktischer Arzt nieder.

Oboleich er nun scbon durch mehrere Jahre Botanik studirte, war es ihm doch nicht möglich, während des unsteten Aufenthaltes als Militär sich ein Herbar anzulegen. Nunmehr schritt er mit regem Fifer an diese Arbeit, und aus dem Jahre 1798 stammen die Anfänge seines später riesenhaft angewachsenen Herbars. Nach einem noch vorhandenen Ausweise zählte selbes schon 1820 über 30.000 Exemplare.

In Mähren blieb er nur Ein Jahr und übersiedelte dann auf die gräflich Medniansky'sche Herrschaft Weszele im Neutraer Comitate, wo er fünf Jahre verblieb. Er erhielt einen Antrag, auf die Herrschaft Rownye des Grafen Aspermonte im Trentschiner Comitate zu übersiedeln, und leistete ihm Folge. Hier, mitten in einer reichen Flora und nahe den Karpaten, weilte er 15 volle Jahre. Jeden Angenblick, den ihm die Berufsgeschäfte übrig liessen, widmete er dem Studium der Pflanzenwelt. Je mehr er sich in das Studium der Botanik vertiefte, desto reger wurde der Wunsch in ihm, sich selbem ungestört einzig und allein widmen zu können. Als daher 1820 die Stelle eines botanischen Obergärtners der Universität in Pest offen wurde, bewarb or sich sogleich darum. Man zögerte nicht, diese Stelle einem Manne zu geben, der damals schon einen so guten Namen in der Wissenschaft hatte, dass man überzougt sein musste - dass seine Befähigung weit über die Erfordernisse dieses Postens hinausreichte. Durch volle 20 Jahre blieb er nun in Pest. Der botanische Garten der Universität zeichnete sich unter seiner Leitang nicht nur durch Reichhaltigkeit der cultivirten Planzenarton aus, sondern weit mehr noch dadurch, dass da neue Pfauzenformen der damals noch wenig bekannten Flora Ungarns zum ersten Male zur Anschaung gebracht wurden, und von hier ans ibren Weg weiter in die übrigen botanischen Gärten Furopas nahmen.

Der Glanzpunkt seiner Leistungen als botanischer Obergärtner war jedoch die Anlage einer reichhaltigen Alpenpflanzen-Cultur. Berücksichtigt man, dass nach seiner Culturmethode die Alpenpflanzen durch Jahre hindurch nicht degenerirten und noch obendrein im Pester Klima - so muss man selber rolle Bewunderung zollen.

Während der 20 Jahre, die er diesen Posten inne hatte, übte er selur wenig ärztliche Praxis aus, was jedoch nicht hinderte, dass er als ein sehr scharfer Diagnostiker häufig zu Concilien beigezogen wurde, und zwar bis in die allerhöchsten Kreise hinauf. In Folge eines solchen Concils wurde $\mathrm{ihm}$ ron einer inländischen Universität das Doctor-Diplom angetragen, allein er schlug es aus.

1840 erbielt er über sein Ansuchen seine Pensionirung und verliess am 6. April Pest, um nach Petersburg zu reisen. Er wollte 
seinen ältesten Sohn besuchen, der sich dort als Handelsgärtner etablirt hibtte und als solcher noch heute dort lebt, ferner wollte or die Flora Russlands aus eigener Anschanung kennen lernen, endlich versuchen, ob er nicht dort sein Herbar verkaufen könne.

Diese Reise erforderte zu jener Zeit 45 Tage! Schon wälurend derselben hatte er, angeachtet er mit Regierungspass und Recommandations-Briefen hoher Persönlichkeiten ausgerüstet war, wiederholt Revisionen und andere Behelligungen zu überkommen. Missgestimmt langte er am 21. Mai 1840 in Petersburg an.

Er versuchte über die auf der Reise erlittenen Kränkungen Klage zu führen, allein mit üblem Erfolge. Seine botanischen Ausflüge um Petersburg erregten entweder wirklich Verdacht oder wurden als Vorwand dazu verwendet -- kurz er spürte sich plötzlich überwacht - Ursache genug, um am 30. October 1840 Petersburg zu verlassen und über Riga nach Dresden zu eilen; wo er arm 27. November anlangte.

Froh, die russische Grenze im Rücken zu haben, wurde ihm der Aufenthalt in Dresden doppelt angenehm durch die Hnld und Gewogenheit, mit der ihn König Johann auszeichnete. Auch mit dem Herbar wurde Ordnung gemacht, und Rochel überliess es dem Könige gegen eine lebenslängliche Leibrente, die er jedoch kaum über 6 Jahre genoss.

An 21. März 1841 verliess er Dresden und langte, über Wien reisend, am 9. April in Pest an. Dort nahm er schweren Abschied von seinem Herbar, welches er durch 42 Jahre eifrig zusammengetragen und vermehrt hatte. Er verpackte und versendete es an seinen neuen Bestimmungsort.

Seines Verbleibens war nun nicht länger in Pest. Er reiste nach Graz zur Versammlung der doutschen Naturforseher und Aeizte, welche selbes Jahr dort tagte. Es gefiel ihm in Graz so wobl, dass or sich entschloss, dort seinen bleibenden Aufenthalt zu nehmen and den Rest seiner Tage daselbst zin verleben.

Er starb am 12. März 1847 allda.

Rochel war noeh als Greis eine sch:öne, hühnenhafte Erscheinung und muss in seiner Jugeud ein bildschöner Mann gewesen sein. Im Frühling 1842 lernte ich ihn kennen und verbrachto bis October 1846, wo ich Graz verliess, meine ganze freie Zeit bei itm!

Seine Beschäftigung bestand theils in der Anlegung eines neuen Herbars, theils in der Cultur von Alpenpflanzen. Er wohnte am grossen Glacis im Eckhause am Eingange in die Attems-Gasse. Im Hofraume dieses Hauses in eiver Ecke wurden ibm 7 Quadratklafter Bodens überlassen, die er einfrieden liess, und wo wir einen Alpengarten anlegten, in welchem gegen 400 Arten Alperpflanzen mit der grössten Sorgfalt gepliegt wurden. Erzherzog Johann fand es der Mühe werth; dieses Miniatur-Gärtchen oft zu besichtigen, und war voll Lobes und Bewunderung über das unübertrefiliche Gedeihen der Pflanzen.

Nebst der Pflege seines Gärtchens beschäftigte Rochel hampt- 
sächlich die Neu-Anlage seines Herbars. Wir excursirten nicht nur fleissig in der Umgebung von Graz, sondern in seinem 75. Jahre war er mit mir noch rüstig am Schöckel. Den Winter hierauf fingen lann seine Körperkräfte zu schwinden an - und or wurde bei voller Geistesfrische immer schwächer und schwächer und erholte sich nimmer!

Rochel schrieb nebst drei grösseren Werken mohrere Aufsätze für Fachblätter. Mir sind von seinen Schriften bekannt:

1. Naturhistorische Miscellen über den nordwestlichen Karpat in Ungarn, mit einer Karte, Pest 1821.

2. Pflanzen-Umrisse. Wo dieser Aufsatz veröffentlicht wurde, ist mir nicht erinnerlich.

3. Plantae Banatus rariores. Pesthini 1828. Folio mit $40 \mathrm{Ta}-$ feln und 2 Karten. Diess ist wohl sein Hauptwerk. Die Tafeln und Karten sind eigenhändig und meisterhaft von ihm selbst gezeichnet und werden beständig zu den Abbildungen besten Ranges gezählt werden,

4. Erster Nachtrag (Flora 1831).

5. Botanische Reise in das Banat. Pest 1838.

6. Beiträge zur Kenntniss der Gattung Mentha (Linnaea 1838).

7. Waldsteinia trifolia Rochel (Linnaea 1839).

Rochel's Werke sind sehr selten, und jede botanische Bibliothek ist stolz auf ihren Besitz und rechnet sie zu ibren schönsten Zierden. Es hat damit sein eigenes Bewandtuiss. Die unter 1, 3 und 5 verzoichneten Werke liess or auf eigene Unkosten drucken und gab sie nur stückweise dem Buchbändler. Vor seiner Abreise nach Petersburg wollte er sich der ganzen Auflagen entledigen, allein der Buchhändler glaubte den Preis wegen der bevorstehenden Abreise herabdrücken zu können. Rochel gab ihm bis Abend Bedenkzeit. Der Buchhändler kam nicht, Rochel machte Fener in dem ofen und brachte die ganze Nacht damit zu, seine ganzen Auflagen zu verbrenuen. Wohl kam der Buchhändler den anderen Morgen und war bereit, jeden Preis zu bezahlen -. es wurde ihm ein Haufe Asche gewiesen.

Rochel hielt sehr wenig auf Auszeichnungen, und es war ans ihm nicht herauszubringen, welche ihm zu Theil geworden sind. Aus seinem Nachlasse sind nur die folgenden ersichtlich:

Die Societas botanica Ratisbonensis ernannte ihn im April 1804 zu ihrem Ehrenmitgliede.

Die königl. botan. Gesellschaft in Regensburg ernannte ibn am 8. März 1821 zı ihrem Mitgliede.

Die kaiserl. Leopoldinisch-Carolinische Alademie der Naturforscher ernannte inn laut Diplom vom 10. Juni 1829 zu ihrem Mitgliede mit dem Beinamen "Scopoli“. Diese Auszeichnung war die einzige, die ihn freute, und deren er ofter Erwähnung that.

Römer et Schultes trennten das Genus Echinospermum und benannten das so neugeschaffene Genus Rochelia.

Die grosse Zahl der von ihm entdeckten Pflanzen, sowio der- 
jenigen, die nach ihm benannt worden sind, eivzeln aufzuzählen, wäre hier viel zu weitläufig.

Eine Auszeichnung, die den grössten Ehrgeiz zu befriedigen im Stande wäre, wurde ihm erst im August 1882 zu Theil. Der Karpaten-Verein beschloss nämlich in seiner zu Schmecks abgehaltenen Generalversammlung einhellig: "den unmittelbar vom Krivan westlich ausgehenden Felsgrat, der früher keinen Namen hatte, RochelSpitze zu benennen". So wird sein Name in einer ihm zu Lebzeiten sehr lieben Region fortleben; denn er hat den Krivan seit 1804 wiederholt bestiegen und war der Erste, der dort botanisirte, lange vor Wahlenberg.

Seine Naturanschauungen neigten sich längst zum Darwinismus. In seinen Menthen gibt er schon den Kalendermachern den Rath, ihre Schröpf- und Aderlass-Tabellen in Hinkunft mit einem Anhange zu versehen, aus dem man erfahren könne, ob die neuen Species besser beim aufnehmenden oder abnehmenden Monde gedeihen. Weiters fragt er, ob nicht manche ephemere Species vielleicht auf einen Abortus im sensorium commune authoris zurückzuführen seien.

Ich erlaube mir noch, hier drei seiner praktischen Verfahren mit wenig Worten zu besehreiben.

1. Anlangend die Cultur der Alpenpflanzen, so war es seine Maxime, die Pflanze vorerst vollkommen von der mitgebrachten Erde zu reingen und sie in sehr magerem Boden möglichst fest einzusetzen. Die abgebeutelte Erde wurde sorgfältig aufbewahrt und mit selber die Pflanze von oben von Zeit zu Zeit "gefüttert". Bei dieser Füttertung kommen überdiess dann häufig aus in der Erde schlummernden Samen Pflanzen zum Vorschein, die man früher nicht in den Garten gebracht hatte. Ferner sagte er immer: die Alpenpflanze will Feuchtigkeit, nicht Nässe - letztere schadet ihr sogar in den äussersten Wurzelspitzen! ferner vertragen diese Pflanzen tiefen Schacht-, nur keinen Deckschatten.

2. Seine Pflanzentrocknungs-Methode war anch originell and bietet grosse Vortheile. Er legte die Pflanzen ein und presste sie so lange, bis sie welkten, $d$. h. beim Oeffnen der Bogen flach liegen blieben und sich nicht wieder aufrichteten. Dann legte er die Bogen mit den Pflanzen dachziegelförmig übereinander in die Luft, bis sie zu schrumpfen anfingen. Dann presste er sie durch 4-5 Stunden wieder glatt und wiederholte dieses Verfahren, bis die Pflanzen trocken wurden. Diese Art Pflanzen zu trocknen hat bedeutende Vortheile, die Pflanzen trocknen schnell, und behalten die meisten lange ihre F'arben, endlich braucht man viel weniger Papier, was besonders auf Reisen wichtig ist.

3. Seine Zeichnungen von Pflanzen führte er auch in eigener Weise aus. Er zeichnete alle Pflanzen mit der Feder, hatte dabei jodoch drei Schalen mit Tusche, in deren erster die Tusche sehr licht, in der zweiten dunkler, in der dritten ganz schwarz angerieben war. Man erspart damit das Schattiren und bringt mit ein- 
zelnen Liniea sehr schöne Lichteffecte hervor. Ein derlei Blatt von ihm mit specieller Widmung für mich gab ich dem Tatra-Museum in Felka.

War Rochel in der Wissenschaft gross, so war er noch grösser als Mensch! Er war ein eiserner Charakter im vollsten Sinne des Wortes! Dor einzige Vorwurf, den man ibm machte, war der, dass er zu "schroff" auftrat. Schönfärberei in der Wissenschaft u. dergl. geisselte er schonungslos und in schärfster Weise, ohne alle Rücksicht auf die Person.

Ich bewahre als Reliquie von ihm seine mir testamentarisch vermachte "Leiblupe", die ihn durch viele Jahre überall hin begleitete, und ein Stammbuchblatt. Ich theile die Worte des letzteren mit, weil sie charakteristisch sind.

"Lieber junger Freund Ullepitsch! Diess Blättchen mit Wünschen füllen mag ich nicht, weil sie nichts nützen - wenn Sie sich jedoch am Abend Thres Lebens sagen können: Keiner meiner verlebten Tage revet mich, dann haben die Götter Ihnen dasjenige verliehen, was sie nur Jenen geben, denen es voller Fnnst ist, sich die wahre Würde der Menschheit anzueignen".

Er liegt am St. Peter-Friedhofe in Graz begraben. - Friede seiner Asche.

Rohrbach in Oberösterreich, April 1884.

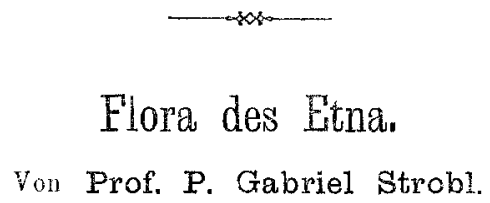

(Fortsetzung.)

952. Helleborus Bocconi Ten. Guss. Syn. et Herb.!, viridis *Raf. II, non L. Wurzelblätter kahl, mit Ausnahme der Hanptnerven ganz lichtgrün, etwas glänzend, kürzer, als der Stengel, fussförmig fiederschnittig, die Fiedern handförmig 2-5theilig, Theile lang linear-lanzettlich ( 4 bis $12 \mathrm{Mm}$. breit, 8-10 $\mathrm{Cm}$. lang), scharf gesägt, Nerven der Blattunterseite sehr hervorspringend netzig; dio unteren Stengelblätter kurz gestielt, die oberen sitzend, alle spärlicher getheilt mit kürzeren Zipfeln; Stengel meist zweitheilig mit einblüthigen Aesten; Blüthen gestielt, mit eiförmigen, stumpfen, grünen Kelchblättern; Balgfrüchte abgestutzt, querrunzelig. Meine Exemplare des multifidus Vis. aus Dalmatien und Montenegro sind von denen Neapels und Siciliens nicht verschieden! In Hainen nnd Bergwäldern: Waldregion des Etna (Raf. II), um Catania? von Cajtorina gesammelt (Herb. Torn.!). März, April.

953. Nigella damascena L. *Cat. Cos., Guss. Syn. et "Herb.! Unter Saaten, auf Rainen, steinigen und grasigen Abhängen bis $3000^{\prime}$ gemein: Um Catania überall (!, Herb. Torn., Herb. Guss.!), 